\title{
Den Dino piksen
}

Liebe Leserin, lieber Leser,

die arme Mademoiselle Perrette kann einem wirklich leidtun, denn sie ist quasi zum Synonym schlechthin für menschliche Dummheit geworden. Dabei hatte die junge Frau doch auf dem Weg zum Markt lediglich bereits im Kopf errechnet, was sie denn für ihre Ware als Gewinn erzielen könnte. Diese bestand aus Kuhmilch und ging vor dem Verkauf im wahrsten Sinne verschütt; aber glücklicherweise existiert das Milchmädchen nur in der Fiktion der Fabel.

Ganz real hat sich gerade in grüngesinnten Köpfen dafür die Mär vom sauberen Elektrofahrzeug festgebissen. Das fährt ja bekanntlich mit Strom, da kommen ergo keinerlei klimaschädlichen Abgase raus, und deshalb ist das Ding umweltfreundlich. Während ich bei derartigen Perettereien bislang meist nur die Augen verdrehte, und dachte „....der kommt bei uns aus der Steckdose“, ballt sich derzeit die Faust wieder in der Hosentasche.

Strom ist im zu Ende gehenden Jahr 2021 nämlich wieder deutlich dreckiger geworden. In den ersten sechs Monaten stieg die Stromerzeugung aus konventioneller Energie in Deutschland gegenüber dem ersten Halbjahr 2020 um 20,9\% und machte einen Anteil von 56,0 \% an der gesamten Stromerzeugung aus, wobei Kohle um 35,5 \% zulegte. Klimaziele mit Elektroautos erreichen - selten so gelacht.

Aber vielleicht gäbe es da ja eine Möglichkeit, BEVs mit wirklich grüner Energie zu laden. Man müsste dazu nur den behäbigen Dino namens deutsche Automobilindustrie ein wenig piksen. Und eventuell ist die Nadel dafür sogar schon gezückt. In China ist letzten Monat ein Industriestandard in Kraft getreten, mit dem das Modell des Wechselakkus geregelt wird. Statt endloser Zwangsaufenthalte an der Ladesäule wird einfach nur die Batterie innerhalb einer Minute gewechselt, und sie könnten mit $100 \%$ ökologischer Energie aus Niedriglastzeiten geladen werden. Zugegeben, die Idee ist alles andere als neu und wurde vom Dino immer wieder abgebügelt. Das System von Wechselakkus in Automobilen sei „technisch nicht realisierbar“ und es bedürfe gar der „Planwirtschaft“ dieses umzusetzen, hieß es. Beides ist natürlich ebenso hanebüchen wie es weiland zum Beispiel die fast wortgleiche Argumentation von selbiger Stelle zum Katalysator gewesen ist.

Man wird sehen, ob der Autosaurus germanicus nicht schneller als gedacht aus dem Quark kommt, wenn die Konkurrenz hierzulande nach den Gesetzen der Marktwirtschaft erste Erfolge feiert. Erst im November ist ein - deutscher - Hersteller mit genau solch einem Wechselakku-System an die Öffentlichkeit getreten. Bringt mir das Popcorn, es könnte spannend werden ...

Herzliche Grüße, Ihr

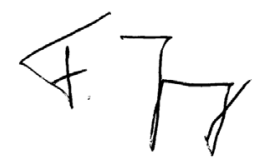

Frank Jung

Redakteur

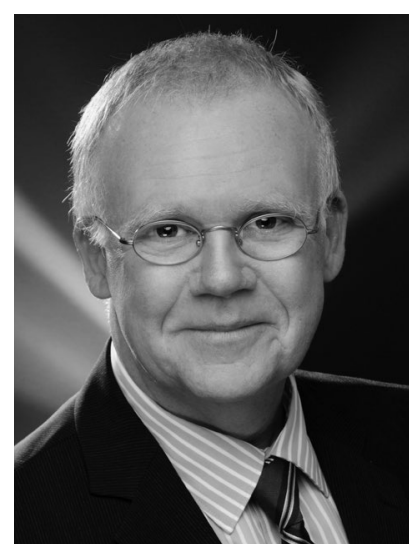

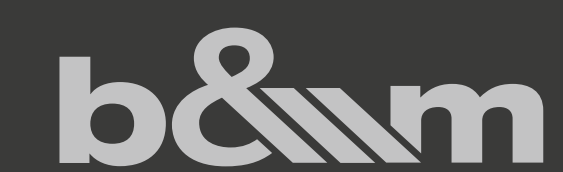
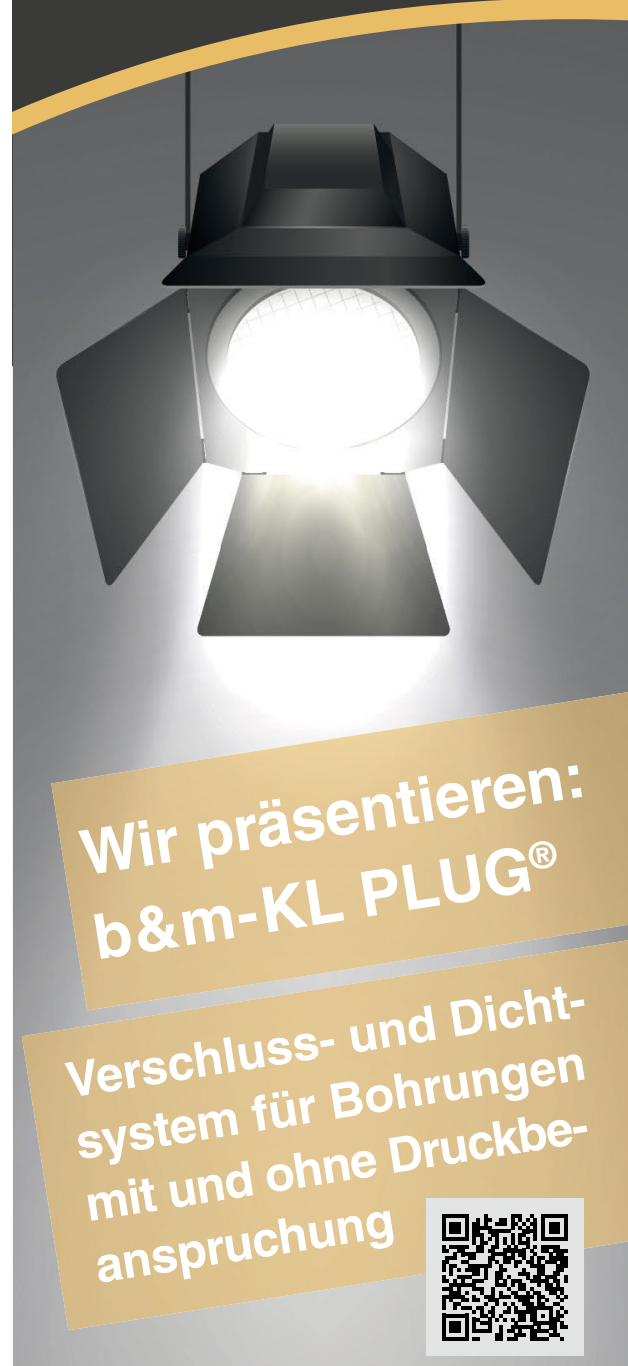

Wir präsentieren: b\&m-KL PLUG ${ }^{\circledR}$ Verechluss- und Dichtfuir Bohrunger chne Druckbe anspruchung

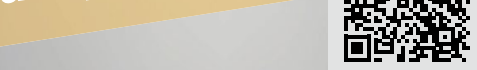

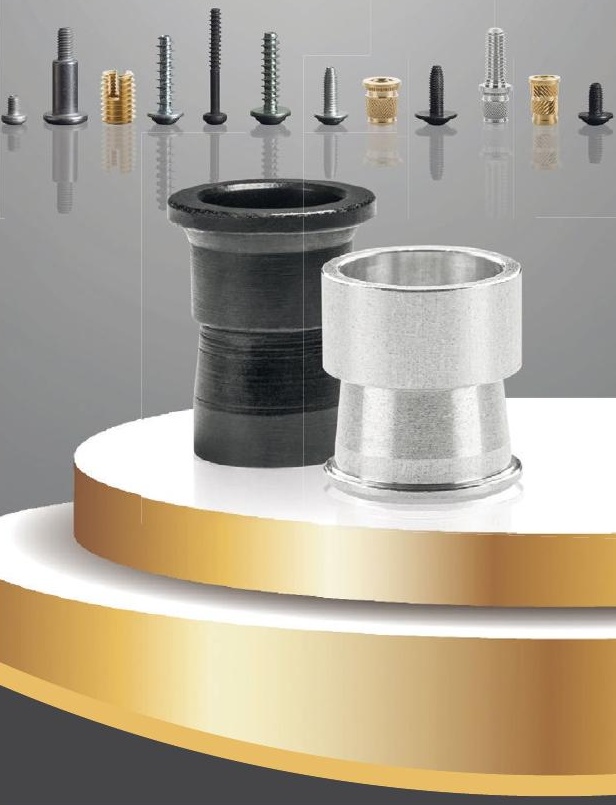

Besuchen Sie uns auf der EUROGUSS / Stand 8-213!

www.baier-michels.com/karten 